\title{
Inhibitory activity of Rhamnolipid produced by Pseudomonas aeruginosa NH22 against Rhizoctonia solani
}

\section{Pseudomonas aeruginosa NH22 الفعالية التثبية للرامنولبد المنتج من بكتريا ضد Rhizoctonia solani}

\author{
Nadhem H. Hayder Gumaa \\ College of Sciencel Baghdad University \\ ناظم حسن حيلر جمعة \\ كلية العلوم \جامعة بغداد
}

\begin{abstract}
Sn the present study, isolation and identification of microorganisms from rhizospher of garden soil with biosurfactant producing ability and characterization of biosurfactants were studied. The results exhibited capability of four isolates for biosurfactant production among six isolates. The isolate Pseudomonas aeruginosa NH22 showed a better emulsifier producer, therefore it selected for biosurfactant production and antifungal activity in the present study. Biochemical analysis of partially purified bioemulsifier demonstrated that the biosurfactant contains mono, and di- rhamnolipid with $\boldsymbol{R f}$ values of 0.82 and 0.32 respectively. Rhamnolipid efficiency tested for antifungal activity by determination percentage reduction of radial growth, fresh and dry weight and laccase activity of fungus. Maximum reduction in radial growth $76 \%$, and reduction of biomass obtained at rhamnolipid concentration of $1000 \mu \mathrm{g} / \mathrm{ml}$. Maximum laccase activity obtained $0.921 \mathrm{U} / \mathrm{ml}$ also at rhamnolipid concentration of $1000 \mu \mathrm{g} / \mathrm{ml}$, while reduction about $21 \%$ of the enzyme activity recorded at higher rhamnolipih concentration of $1500 \mu \mathrm{g} / \mathrm{ml}$. The critical micelle concentration estimated to be $200 \mathrm{mg} / \mathrm{l}$, which led to reduce surface tension value of the culture to34 $\mathrm{mN} / \mathrm{m}$.
\end{abstract}

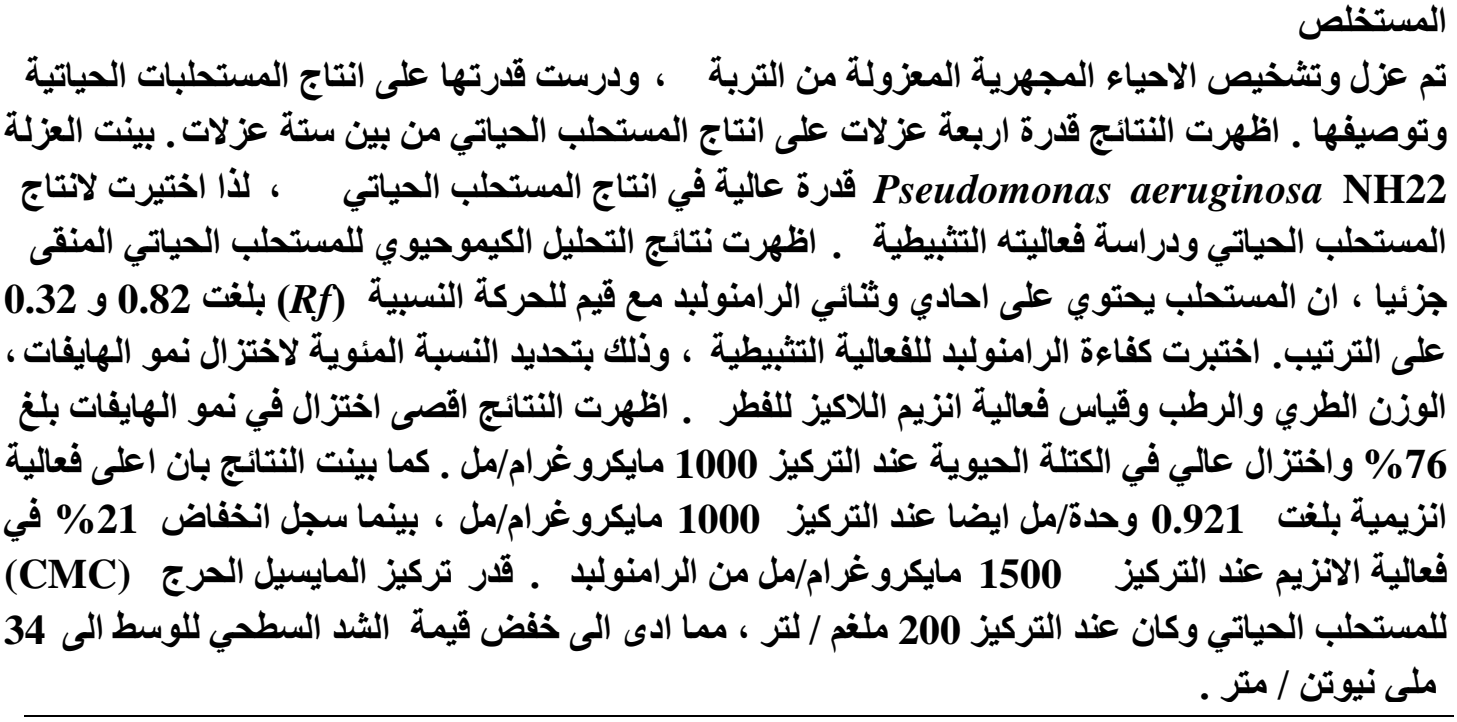

Key Words: Biosurfactant, antifungal activity, enzyme activity, CMC 


\section{Introduction}

Biosurfactants are extracellular macromolecules produced by bacteria, yeast and fungi and in particular by natural and recombinant bacteria when grown on different carbon sources. The microbial surfactants have gained attention in recent years due to their commercial importance, diverse desirable characteristics such as biodegradability, selectively effectiveness, low toxicity, ecological acceptability and their ability to be produced from cheaper substrates. Among the heterogeneous group of biosurfactants, are the rhamnose-containing glycolipids produced by Pseudomonas sp. Rhamnolipid have been known as biosurfactant which is produced by $P$. aeruginosa in fermentation process. Several carbon sources such as ethanol, glucose, vegetable oil, and hydrocarbon have been used to produce rhamnolipid. Microbial surfactants are generally less toxic and more biodegradable than synthetic surfactants. Rhamnolipid biosurfactants specifically produced by $P$. aeruginosa have great potential for industrial, agriculture, medicine application and bioremediation [1].

Among the bacterial genera used in biological control, Pseudomonas and Bacillus species are the most widely studied. Pseudomonas strains are highly amenable for research, because they are fast growing, easy to culture, metabolically versatile and easy to manipulate genetically. Different Pseudomonas strains have the ability to inhibit the growth and activity of a wide range of plant pathogens, including fungi, nematodes and bacteria [2]. Pseudomonas sp. is common inhabitants of soil and rhizosphere environments and has received considerable attention in the areas of bioremediation of xenobiotics and biological control of plant pathogenic fungi [3].

Some Pseudomonas strains have been recognized as antagonists of plant fungal pathogens and antibiotic producers. This is probably due to the abundance of this diverse group of bacteria and their obvious importance in the soils [4]. A single strain of Pseudomonas can produce several different antibiotics. A similar spectrum of antibiotic production has been described in different strains. For instance, Pseudomonas fluorescens strain CHA0 has been known to produce pyrrolnitrin, pyoluteorin, and 2, 4-diacetylphloroglucinol. Antifungal antibiotics produced by Pseudomonas spp. include pyrrolnitrin, phenazines, pyoluteorin, 2, 4diacetylphloroglucinol, rhamnolipids, oomycin A, cepaciamide A, and ecomycins [5]. The rhamnolipids produced by $P$. aeruginosa are composed of mono- or dirhamnose linked to 3-hydroxy fatty acids of various chain lengths. The most abundant rhamnolipid species of $P$. aeruginosa are L-rhamnosyl-3-hydroxydecanoyl-3hydroxydecanoate (monorhamnolipid) and L-rhamnosyl-L-rhamnosyl-3hydroxydecanoyl -3-hydroxydecanoate (dirhamnolipid) [6].

The biosynthesis and biochemistry of rhamnolipids have been extensively studied; however, the exact function of rhamnolipids is still unclear. They seem to play multiple roles, as their presence promotes uptake of hydrophobic substrates and alters cell surface polarity. Rhamnolipids also have antimicrobial activities against other bacteria and fungi. Rhamnolipids are suspected of playing a role in maintaining fluid channels and the detachment of cells from the biofilm community. Swarming motility 
of $P$. aeruginosa is affected by rhamnolipids, most probably by a reduction of surface tension, which causes the surface conditioning needed for efficient colonization [5]. Rhamnolipids produced by strains of Pseudomonas aeruginosa were shown to be highly effective against plant pathogens, including Pythium aphanidermatum, Plasmopara lactucae-radicis, Rhizoctonia solani and Phytophthora capsici. Purified rhamnolipids caused cessation of motility and the lysis of entire zoospore populations within $1 \mathrm{~min}$. The introduction of a rhamnolipid-producing strain into a recirculating hydroponic system gave good, although transient, control of $P$. capsici on pepper. Also rhamnolipid $\mathrm{B}$, produced by $P$. aeruginosa $\mathrm{B} 5$, has not only lytic effects on zoospores but also inhibitory activity against the spore germination and hyphal growth of several other pathogens. Mycelial growth of $P$. capsici and spore germination of Colletotrichum orbiculare were inhibited in vitro, and the diseases caused by these pathogens were suppressed in pepper and cucumber plants, respectively, by application of purified rhamnolipid B to leaves [3].

Several cyclic lipopeptide (CLP) surfactants with antibiotic properties were recently proposed as biological compounds for the control of plant-pathogenic fungi. Viscosinamide, produced by soil-inhabiting Pseudomonas sp. Strain DR54, was shown to induce encystment of Pythium zoospores and to adversely affect mycelia of Rhizoctonia solani and Pythium ultimum, causing reduced growth and intracellular activity, hyphal swellings, increased branching, and rosette formation [7]. Exposure to CLPs and other biosurfactants such as rhamnolipids can render zoospores of oomycete pathogens immotile and induce subsequent cell lysis. However, CLPs also have been reported to exhibit antibiotic properties toward fungal root pathogens, resulting in suppression of spore germination and inhibition of hyphal growth [8]. Among the great variety of antifungal metabolites produced by fluorescent Pseudomonas sp., such as cyclic lipopeptides, our attention has been focused on the rhamnolipid biosurfactant. The aim of this study was to isolation and identification of biosurfactant producing bacteria from rhizosphere zone of garden soils, and analysis of that product. Moreover, study the effect of partial purified biosurfactant on mycelium growth, biomass formation and laccase activity of Rhizoctonia solani.

\section{Materials and methods}

\section{Microorganisms and growth conditions}

The bacterial isolates used in this study were isolated from the rhizosphere zone, of the gardens soil, near department of biotechnology/ University of Baghdad. The identification was carried out according to Bergy's Manual of Systematic Bacteriology. The methods used for identification were performed according to manual of methods for general bacteriology [9]. The isolates was maintained on nutrient agar medium (Difco, India) at $30^{\circ} \mathrm{C}$. The Fungus isolate Rhizoctonia solani used in this study was isolated from infected tomato, obtained from Department of Biology/ College of Science/ University of Baghdad. The isolate Rhizoctonia solani was grown on Potato dextrose agar (PDA) and incubated at $25^{\circ} \mathrm{C}$ for $72 \mathrm{~h}$. 


\section{Screening of biosurfactant production isolates:}

To determine the biosurfactant production ability, bacterial isolates were inoculated with mineral salt medium (MSM) [10]. In brief, isolates were inoculated into $50 \mathrm{ml}$ of MSM containing 3\% (v/v) of olive oil and incubated with continuous shaking (150 $\mathrm{rpm}$ ) for $72 \mathrm{~h}$ at $30{ }^{\circ} \mathrm{C}$ using a shaker incubator (Basel Switzerland). Biosurfactant production ability was determined by drop collapse method and surface tension lowering [6,10]. For the drop collapse method, $2.0 \mu \mathrm{l}$ of mineral oil was added to each well of a 96-well microtiter plate lid. The lid was equilibrated for $1 \mathrm{~h}$ at room temperature, and then $5 \mu \mathrm{l}$ of the cultural supernatant was added to the surface of oil. The shape of the drop on the oil surface was inspected after 1min. Biosurfactantproducing cultures giving flat drops were scored as positive (+). Those cultures that gave rounded drops were scored as negative (-), indicative of the lack of biosurfactant production. The surface tension of the cell-free culture was measured employing the De Nouy ring method with a Kruss K6 tensiometer (Kruss GmbH, Hamburg, and Germany). The values reported are the mean of two measurements. All measurements were made on cell-free broth obtained by centrifuging the cultures at $10,000 \mathrm{~g}$ at $4^{\circ} \mathrm{C}$ for $15 \mathrm{~min}$.

\section{Biosurfactant Extraction and Isolation}

Production of biosurfactant was performed using method described by [10]. Briefly, isolate were grown in $500 \mathrm{ml}$ Erlenmeyer flasks, each containing $100 \mathrm{ml}$ of MSM amended with $3 \%(\mathrm{v} / \mathrm{v})$ of olive oil. The flasks were incubated at $30^{\circ} \mathrm{C}$ in a shaker incubator for $96 \mathrm{~h}$. To isolate the biosurfactant, bacteria were precipitated by centrifugation at $10000 \mathrm{rpm}$ at $4^{\circ} \mathrm{C}$ for $15 \mathrm{~min}$. The remaining supernatant liquid was filtered through a $0.22 \mu \mathrm{m}$ pore-size filter (Millipore). Biosurfactant was obtained by adjusting the supernatant $\mathrm{pH}$ to 2.0 using $6 \mathrm{~N} \mathrm{HCl}$ and keeping it at $4{ }^{\circ} \mathrm{C}$ overnight. The precipitate thus obtained was pelleted at $8000 \mathrm{~g}$ for $20 \mathrm{~min}$, dried and weighted. For further purification, the crude surfactant was dissolved in distilled water at $\mathrm{pH} 7.0$ and dried at $60^{\circ} \mathrm{C}$. The dry product was extracted with chloroform: methanol (65:15), filtered and the solvent evaporated. The brown dried material was then extracted three times with methanol. After evaporation, the crude biosurfactant was used for remaining studies.

\section{Rhamnolipid analysis}

The surface active rhamnolipid were isolated according to the method described by [11]. The extracted rhamnolipid were dissolved in chloroform-methanol (9:1) in the concentration of $10 \mathrm{mg} / \mathrm{ml}$, and $2 \mu \mathrm{l}$ of the sample was spotted onto thin-layer chromatography (TLC) plates (silica gel 60 F254; Merck) with dimension of (20 cm $\times$ $20 \mathrm{~cm} \times 0.25 \mathrm{~mm})$. After development in chloroform-methanol-acetic acid (65:15:2), The amino acid content of surfactant was determined using the ninhydrin method, and the lipid content determined by the phenol-sulphuric reaction method, and glycolipid were determined using the molish test $[11,12]$. 


\section{Antifungal activity}

\section{- Effect of Rhmnolipid on radial growth rate of Rhizoctonia solani}

The effect of rhmnolipid on radial growth rate of Rhizoctonia solani was studied on $1 / 5^{\text {th }}$-strength potato dextrose agar $(\mathrm{pH} 7)$. Sterilized growth medium was cooled down to $55^{\circ} \mathrm{C}$ and amended with rhamnolipid to final concentrations of $(0,100,200,400,600$, $800,1000) \mu \mathrm{g} / \mathrm{ml}$; each plate contained $20 \mathrm{ml}$ of growth medium. A plug $(8 \mathrm{~mm}$ ) of $R$. solani mycelium, excised from the margin of 3 day old culture PDA plates, and placed in the centre of the $9.0 \mathrm{~cm}$ diameter Petri plate containing one-fifth strength PDA amended with partially purified rhamnolipid, and incubated at $25{ }^{\circ} \mathrm{C}$. Radial growth rate was measured with a ruler after 3 days. Control plates containing growth medium without addition of rhamnolipid. Percentage of radial growth inhibition were recorded according to the formula, as follows: Percentage of growth reduction $=[(\mathrm{A}-\mathrm{B}) / \mathrm{A} \times 100]$, where: $\mathrm{A}=$ diameter of the control hyphal growth $(\mathrm{mm}), \mathrm{B}=$ diameter of the treated hyphal growth $(\mathrm{mm})[9]$.

\section{- Effect of Rhmnolipid on biomass formation of $R$. solani}

The effects of rhamnolipid on biomass of $R$. solani was studied in clarified $1 / 5^{\text {th }}$ strength potato dextrose broth (PDB, $\mathrm{pH} 7.0$ ); final concentrations of rhamnolipid were $(0,100,200,400,600,800,1000,1250,1500) \mu \mathrm{g} / \mathrm{ml}$. A mycelia plug $(8 \mathrm{~mm})$ was transferred to $9.0 \mathrm{~cm}$-diameter Petri plates containing $20 \mathrm{ml}$ of the growth liquid medium. After incubation at $25^{\circ} \mathrm{C}$ for 3 days, mycelium was collected by centrifugation at $5000 \mathrm{~g}$ for $20 \mathrm{~min}$ and blotted to dry on a Whitman filter paper to determining the fresh weight; after drying at $65^{\circ} \mathrm{C}$ for $24 \mathrm{~h}$, mycelium dry weight was determined; obtained weights were corrected for the weight (fresh and dry) of the agar plugs used to inoculate $R$. solani [2].

\section{- Critical Micelle Concentration (CMC)}

The minimum amount of surfactant required to cause the maximum decrease in surface tension, is an important measure of the surface activity and allows comparison with other surfactants [3]. For determining the critical micelle concentration (CMC), the extract was dissolved in sterile distilled water $(\mathrm{pH} 7.0)$ at concentrations of $(0,25$, $50,100,200,300,400,500) \mathrm{mg} / \mathrm{l}$. Surface tension measurements were carried out with a K6 tensiometer (Kru“ss GmbH, Hamburg, and Germany). Measurements were performed at $25^{\circ} \mathrm{C}$, and sterile distilled water was used to calibrate the tensiometer.

\section{- Assay of laccase activity}

Enzyme activity was determined according to the method described by [13], from the change of optical density $\left(\mathrm{A}_{525 \mathrm{~nm}}\right)$. The assay mixture contained $0.2 \mathrm{mM}$ syringaldazine (dissolved in $60 \%$ ethanol) as substrate and $0.1 \mathrm{M}$ citrate phosphate buffer ( $\mathrm{pH}$ 5.0). The change in absorbance was measured after addition $0.5 \mathrm{ml}$ of acetone as stop solution. Enzyme activity was expressed in the following units: $1 \mathrm{U}=1 \mu \mathrm{mol}$ of syringaldazine oxidized to quinine per min at $25^{\circ} \mathrm{C}$ in $0.1 \mathrm{M}$ citrate phosphate buffer (pH5). Laccase activity was calculated from the following formula:

$\mathrm{A}=10^{6} \Delta \mathrm{E} / \mathrm{C} \Delta \mathrm{t}$. where: $\Delta \mathrm{E}=$ increase in absorbance at $525 \mathrm{~nm}, \mathrm{C}=65000$ (molar absorptive of formed quinine), and $\Delta \mathrm{t}=$ reaction time in seconds. 


\section{Result and Discussion}

\section{Screening of biosurfactant producing microorganisms}

Among six isolates tested for biosurfactant production, four isolates exhibited biosurfactant production using the drop-collapse method and surface tension lowering Table (1). If the culture broth contained biosurfactant, the droplets of the broth in the oil-coated wells collapsed. If not, there was no change in the shape of the droplets. Water and cell free culture broth samples remained beaded, meaning they did not contain any type of microbial surfactant [14]. However, culture supernatants of isolate NH5, NH11, NH22, NH31 showed spreading movement, meaning that they produced biosurfactants. The results of surface tension measurements of four different isolates indicate that isolate $\mathrm{NH} 22$ produces more surface active compounds (biosurfactant), as evident from surface tension lowering, started from first day and continued until 96 $\mathrm{h}$ of growth, and reached $38 \mathrm{mN} / \mathrm{m}$. The isolate completely emulsified olive oil in MSM within $96 \mathrm{~h}$ of cultivation Table (1).

A sensitive rapid method, a drop collapsing test, was advised for screening bacterial colonies that produce surfactants. Drops of cell suspensions of surfactant-producing colonies collapsed an oil-coated surface. [15] used the reduction of surface tension and the emulsify capacity to screen biosurfactant- producing microorganisms. Reduction of surface tension is as a selection criterion for biosurfactant capacity of microorganisms in liquid medium. From the obtained results above, the isolate $\mathrm{NH} 22$ was a better biosurfactant producer. Biochemical analysis performed according to Bergy's manual reviled that the isolate $\mathrm{NH} 22$ belong to genus Pseudomonas aeruginosa. Therefore, the isolate Pseudomonas aeruginosa $\mathrm{NH} 22$ used for biosurfactant production in large quantities to determine antifungal activity in the present study.

Table(1): Surface tension and drop-collapse test results for different isolates growing in MSM containing $3 \%$ olive oil in shaker incubator at $30{ }^{\circ} \mathrm{C}$ for $96 \mathrm{~h}$.

\begin{tabular}{ccc}
\hline Isolates & Surface tension $(\mathrm{mN} / \mathrm{m})$ & drop-collapse \\
NH2 & 55 & - \\
NH5 & 39 & + \\
NH11 & 45 & + \\
NH13 & 51 & - \\
NH22 & 38 & + \\
NH31 & 40 & + \\
\hline
\end{tabular}

\section{Biosurfactant characterization}

The structural analysis of biosurfactants produced by Pseudomonas aeruginosa NH22, were performed by lipid, protein and carbohydrate contents in thin layer chromatography (TLC) analysis. Ninhydrin test was used to detect the presence of amino acids contents of biosurfactants. However when the spots on TLC plates spread with this reagent, the biosurfactant gave negative results, an evident that biosurfactant do not contained to amino acid group. Molisch's test ( $\alpha-$ Naphthol) is a sensitive chemical test for the presence of glycolipids, based on the dehydration of the carbohydrate by sulfuric acid to produce an aldehyde, which condenses with two molecules of phenol resulting in a red- or purple-colored compound [14]. From the 
results of Molisch's test, it was shown that the biosurfactant contains carbohydrate residues. The phenol-sulphuric acid reaction analyzed for lipid content of biosurfactants. The biosurfactant gave the positive results with phenol-sulphuric acid reaction. This means that the biosurfactant obtained in this study have lipid content.

Thin layer chromatography results suggested that the isolated surface-active product from $P$. aeruginosa $\mathrm{NH} 22$ was composed of rhamnolipids. The extracted product was separated on TLC plates with a carrier solvent of (chloroform: Methanol: acetic acid, 65:15:2 by volume). When the plats were visualized by reagents, the product of $P$. aeruginosa NH22 was observed to have two spots. Spot 1 with $R f=0.32$, and spot two with $R f=0.82$. The results were in agreement with Yalcin and Ergene [14], when they analyzed commercially available purified rahmnolipid produced by Pseudomonas aeruginosa on TLC plates. They observed two characteristic spots. The lower (high molecular weights) spot consist of di-rhamnolipid $R f=0.36$, while the higher (low molecular weight) spot consisted mono-rhamnolipids $R f=0.84$. SantosGuerra, et. al., [12], described the active compounds production by Pseudomonas aeruginosa on TLC, with the same solvent system. The $R f$ values obtained by these authors are 0.4 and 0.8 for di- and mon-orhamnolipid respectively. The results of TLC analysis showed that the crude product contained di and mono-rhamnolipid with $R f$ values of 0.37 and 0.84 respectively. The results in the present study indicated that the isolate $P$. aeruginosa $\mathrm{NH} 22$ most probably produced the same rhamnolipids as mentioned above.

\section{Antifungal activity}

The antifungal activity of partial purified rhamnolipid and their effects were studied on $1 / 5^{\text {th }}$ - strength potato dextrose agar (PDA) by determining radial growth rate, percentage of growth inhibition, fresh and dry weights of Rhizoctonia solani biomass. It found that the partially purified rhamnolipid surfactant inhibited radial growth rate of $R$. solani. The antifungal activity increased with increasing concentration of partially purified rhamnolipid. The reduction in radial growth rate ranged from 18 to $76 \%$ at a rhamnolipid concentration of 100 to $1000 \mu \mathrm{g} / \mathrm{ml}$, Table (2) and Figure (1). One of the main modes of biosurfactants action, including rhamnolipid and cyclic lipopeptide (CLP) involves the formation of ion channels in the plasma membrane of the target organisms leading to cytolysis [2]. CLP produced by soil-inhabiting Pseudomonas strain DR54, was shown to induce encystment of Pythium zoospores, and also inhibit mycelial growth of Rhizoctonia solani and Pythium ultimum causing reduced growth and intracellular activity, hyphal swellings, increased branching and rosette formation [2]. [2] investigate the effect of purified CLP on mycelial growth of Phytophthora infestans on $1 / 5^{\text {th }}$ strength PDA. The results indicated that, mycelial growth of the fungus inhibited at a CLP concentration of $50 \mu \mathrm{g} / \mathrm{ml}$ and higher, caused increased branching of hyphae. 
Table(2): Radial growth rate and reduction percentage of radial growth for Rhizoctonia solani cultivated on one-fifth strength PDA amended with different concentration of rhamnolipid.

\begin{tabular}{ccc}
\hline $\begin{array}{c}\text { Concentration of } \\
\text { rhamnolipid }(\mu \mathrm{g} / \mathrm{ml})\end{array}$ & $\begin{array}{c}\text { Radial growth rate after 3 } \\
\text { days }(\mathbf{m m})\end{array}$ & $\begin{array}{c}\text { Reduction of radial } \\
\text { growth }(\%)\end{array}$ \\
$\begin{array}{c}\text { (control) } \\
100\end{array}$ & 83 & 0 \\
200 & 68 & 18 \\
400 & 61 & 26.5 \\
600 & 58 & 30 \\
800 & 45 & 46 \\
1000 & 25 & 70 \\
\hline
\end{tabular}

Results in Figure (2) showed the growth of $R$. solani in liquid media (PDB), growth of $R$. solani was significantly inhibited at rhamnolipid concentration of $1000 \mu \mathrm{g} / \mathrm{ml}$. Fresh and dry weight of fungus decreased logarithmically with increasing concentrations of rhamnolipid reaching maximum reduction in biomass at rhamnolipid concentration of $1000 \mu \mathrm{g} / \mathrm{ml}$. [2] also studied the effect of CLP on mycelial growth, fresh and dry weight of Phytophthora infestans on $1 / 5^{\text {th }}$ strength PDB. The results showed that the mycelial growth inhibited at a CLP concentration of $10 \mu \mathrm{g} / \mathrm{ml}$ and higher, fresh and dry weight of Pythium infestans decreased logarithmically with increasing concentrations of CLP reaching the maximum reduction in biomass at CLP concentration of $50 \mu \mathrm{g} / \mathrm{ml}$ and higher.

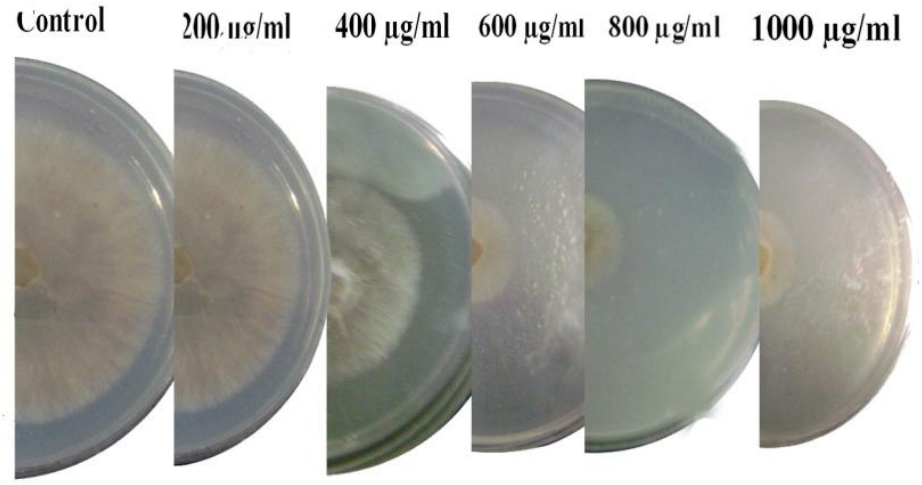

Fig (1): Effect of rhamnolipid on mycelial growth of Rhizoctonia solani on PDA amended with different concentrations of rhamnolipid after 3 days cultivation at $25{ }^{\circ} \mathrm{C}$.

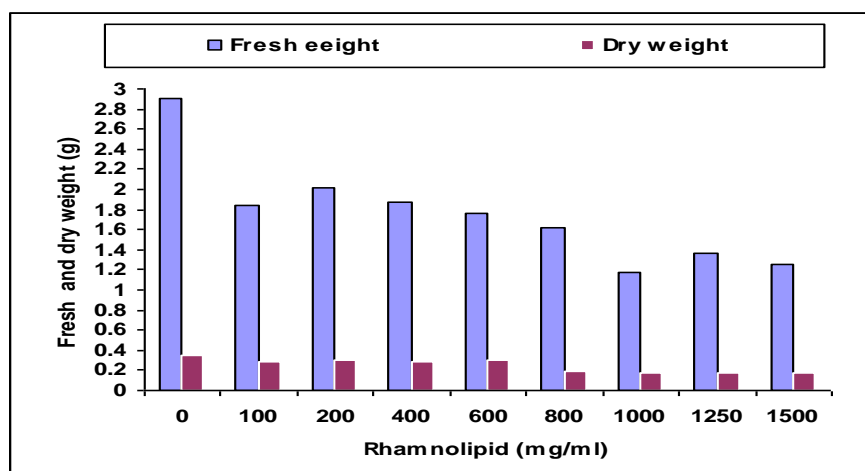

Fig (2): Effect of rhamnolipid on biomass (fresh and dry weights) of Rhizoctonia solani grown on PDB amended with different concentrations of rhamnolipid after 3 days cultivation at $25{ }^{\circ} \mathrm{C}$. 
[16] studied antifungal activities of the crude lipopeptide biosurfactant from Bacillus natto ASA at different concentrations (0.8-3.2) g/L using disc diffusion method. Biosurfactant exhibited interesting and antifungal activities. The antifungal activity increased with increasing concentration of biosurfactant and maximum zone of inhibition obtained (48.8) $\mathrm{mm}$ with Botrytis cinerea at a biosurfactant concentration of $3.2 \mathrm{~g} / \mathrm{l}$. [17] found effective antifungal activity of rhamnolipid and sophorolipid against plant and seed pathogenic fungi. A rhamnolipid mixture obtained from Pseudomonas aeruginosa AT10 showed excellent antifungal properties against Aspergillus niger at concentration of $(16 \mathrm{mg} / \mathrm{ml})$, Chaetonium globosum, Pnicillum crysogenum, Aureobasidium pullulans (32) $\mathrm{mg} / \mathrm{ml}$, and the phytopathogenic Botrytis cinerea and Rhizoctonia solani $(18 \mathrm{mg} / \mathrm{ml})$. Nielsen, et al., [18] studied the role of CLP compounds produced by of fluorescent Pseudomonas sp. in the biological control of pathogenic microfungi ( $R$. solani) on PDA medium. The results demonstrated that the highest level of antagonism against microfungi obtained, and with zone of inhibition $26 \mathrm{~mm}$ in contrast with zone of control $60 \mathrm{~mm}$. [8], mention the effect of cyclic lipopeptide surfactant produced by Pseudomonas fluorescens SS101 for suppression of complex Pythium sp. on nutrient broth yeast, amended with partially purified (70)\% CLP. Maximum reduction in radial growth obtained at $48 \mathrm{~h}$ incubation, and ranged from 46-96\% among Pythium sp. isolates at a CLP concentration of $500 \mu \mathrm{g} / \mathrm{ml}$.

Recently, it was observed an antifungal activity of rhamnolipid against Candida albicans and Candida krusei [5]. The antimicrobial effects of biosurfactants can be explained by the structures of biosurfactants resembled to cell membrane. Biosurfactants are amphipathic molecules with hydrophilic moiety consisting of amino acids or peptides anions or cations; mono-, di-, or polysaccharides; and a hydrophobic moiety consisting of unsaturated, saturated, or fatty acids. Insertion of fatty acids components of biosurfactants into a cell membrane caused significant ultra structural changes in the cells such as ability of the cell to interiorize plasma membrane. Also, antimicrobial effects of biosurfactants could be that the bleb formation represented an increase in the size of the membrane due to insertion of lipid material. One explanation of the antimicrobial effect of biosurfactants is the adhering property of biosurfactants to cell surfaces caused deterioration in the integrity of cell membrane and also breakdown the nutrition cycle. All these cumulative effects can be explained the antimicrobial effects of biosurfactants [14].

As mentioned above, rhamnolipid and CLP possess additional antimicrobial properties with potential for limiting disease incited by fungi and oomycetes. Evaluation of growth for Rhizoctonia solani indicated that rhamnolipid possessed antibiotic properties toward this microfungus; however, complete inhibition was not achieved for Rhizoctonia solani isolate even at the highest test concentration. Therefore further purification of rhamnolipid required to increase the effectiveness of produced biosurfactant. 


\section{Critical micelle concentration (CMC) of biosurfactant}

Critical micelle concentration is defined by the solubility of a surfactant within an aqueous phase and is commonly used to measure the efficiency of a surfactant. No further drop in the surface tension occurs as the amount of surfactant exceeds the CMC because the emulsion is already saturated [16]. The CMC of the crude biosurfactant was estimated to be around $200 \mathrm{mg} / \mathrm{L}$ and the minimum surface tension of biosurfactant obtained was $34 \mathrm{mN} / \mathrm{m}$ Figure (3).

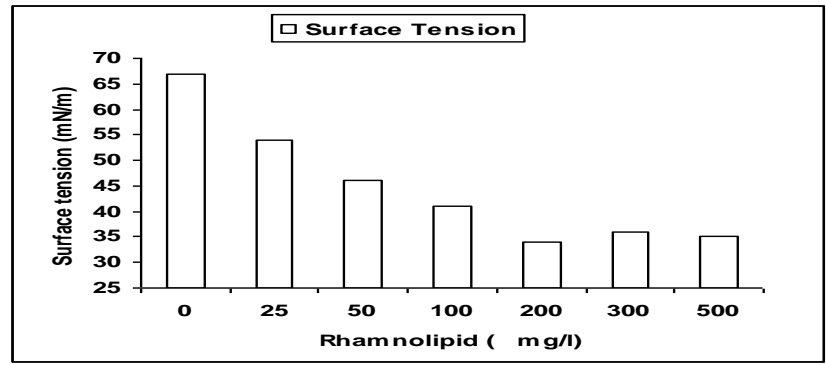

Fig (3): critical micelle concentration of partial purified rhamnolipid at different concentration of biosurfactant in distilled water at $\mathbf{p H}=7$.

In a previous study [19], the rhamnolipids produced by $P$. aeruginosa UG3 lowered the surface tension to $31.4 \mathrm{mN} / \mathrm{ml}$ and achieved a CMC at $30 \mu \mathrm{g} / \mathrm{ml}$. The CMC of the surface-active extract obtained from $P$. fluorescens SS101 was $25 \mu \mathrm{g} / \mathrm{ml}$ [3]. The biosurfactant produced by Bacillus licheniformis JF-2, with properties similar to those of surfactin, lowered the surface tension to $27 \mathrm{mN} \mathrm{m} \_1$ and reached the CMC at 20 $\mu \mathrm{g} / \mathrm{ml}$ [20]. Also the surfactin produced by B. subtilis ATCC 21332 with a CMC of $250 \mathrm{mg} / \mathrm{L}$ and the minimum surface tension $27.9 \mathrm{mN} / \mathrm{m}$ was obtained [16]. The produced biosurfactant in the present study was not effective as many of biosurfactants described in the literature, it should be noted that the biosurfactant studied here was not purified enough as the ones described in the literature. The observed results in the present study showed that the maximum reduction of radial growth obtained at rhamnolipid concentration of $1000 \mu \mathrm{g} / \mathrm{ml}$ or $(\mathrm{mg} / \mathrm{l})$, while CMC achieved at $200 \mathrm{mg} / \mathrm{l}$. Therefore further purification for produced biosurfactant required to increase effectiveness and surface activity of biosurfactant, and decreased the critical micelle concentration.

\section{Laccase activity of $R$. solani}

Fungal laccase mainly extracellular enzymes. They are heterogeneous group of glycoprotein with a carbohydrate content of (10-60)\%. There are differences in the structural components of laccases from different sources. Their common features are copper containing glycoproteins. The carbohydrate content varies depending on the source of substrate. Numerous compounds able to form stable copper complexes have been used as inhibitors especially, sulfhydryl organic compounds, dithiothreitol, thioglycolic acid, cysteine and sodium azide [13]. In the present study an attempt to investigate the relation ship between rhamnolipid (fatty acid and rhamnose) containing biosurfactant and laccase inhibition of $R$. solani.

The results in Figure (4) showed that the enzyme activity increased with increasing concentration of rhamnolipid, and maximum activity $0.921 \mathrm{U} / \mathrm{ml}$ obtained at rhamnolipid concentration of $1000 \mu \mathrm{g} / \mathrm{ml}$, above this concentration the enzyme was 
inhibited. Reduction about $21 \%$ of the enzyme activity recorded at higher rhamnolipid concentration of $1500 \mu \mathrm{g} / \mathrm{ml}$.

A possible structure-function relationship between the hydrophobic fatty acid tail, together with the amphiphilic property of the peptide and glycolipid surfactant, structure may finally play an important role in penetration and binding of rhamnolipid within biological membranes. This in turn may support their role as surfactants and as antibiotics, e.g., disrupting membrane functions leading to excess $\mathrm{Ca}_{2}$ influx into target cells, which led to destruction cell wall of microfungus especially at high concentration [18]

In the present study, the rhamnolipid produced from $P$. aeruginosa $\mathrm{NH}$ isolate reveled the inhibition towards the $R$. solani laccase, especially at concentration of $1250 \mu \mathrm{g} / \mathrm{ml}$ and higher. These properties most probably resemble in their action to cell wall degrading enzyme (protease and chitinase) produced by Pseudomonas aeruginosa. In the similar study of [18], the CLP producing Pseudomonas fluorescens $\mathrm{V}_{2}$ and $\mathrm{V}_{3}$ demonstrated the largest inhibition towards R. solani, also had the most complete array of cell wall degrading enzymes (protease and chitinase).

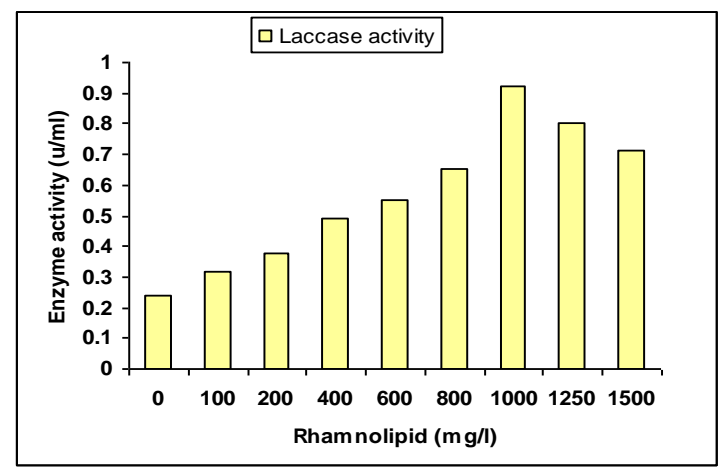

Fig (4): Laccase activity of Rhizoctonia solani at different concentration of rhamnolipid in PDB medium after 3 days of cultivation at $25^{\circ} \mathrm{C}$

The general impact of surfactants in promotion of protein secretion is likely to involve interactions with the lipid components of cell membranes in a manner which facilitates secretion. It should be noted that most of the observations related to the positive effects of surfactants on secretion of extracellular enzymes relate to eukaryotic organisms which release enzymes from intracellular organelles through exocytosis. This observation suggests in our study that surfactants may promote this exocytosis by interaction with cell and organelle lipid membrane components, and enzyme activity increased logarithmically, until reaching inhibitory concentration at $1250 \mu \mathrm{g} / \mathrm{ml}$, above this concentration the enzyme activity adversely affected [21]. [21] also mentioned that the low concentrations of the nonionic surfactant, polyoxyethylene laurylether; C30 H62 O10, increased the activity of cholesterol oxidases from Streptomyces hygroscopicus (SCO) and Brevibacterium sterolicum (BCO) in aqueous media containing propanol as a substrate solubilizer while at higher surfactant concentrations the opposite effect occurs. The oxidation of ophenylenediamine was catalyzed in various anhydrous organic solvents by a surfactant laccase complex, prepared by a novel preparation technique in water-in-oil (w/o) emulsions [22]. 
In the present study, the syringaldazin used as substrate to document laccase activity. The results indicated in Figure (4) that the low-rhamnolipid concentration in PDB liquid medium supported a high and stable laccase activity, while the concentration of $(1250 \mu \mathrm{g} / \mathrm{m})$ and higher demonstrated relatively strong antagonism toward $R$. solani laccase in this medium. [23] showed that the P. fluorescens DR54 isolate produces both an antibiotic compound (CLP) and a cell wall-degrading enzyme (endochitinase), which may act alone or in synergy against mycelial growth and enzyme activity of $R$. solani and Pythium ultima.

\section{References}

1. Onbasli, D. and Aslim, B. (2008). Determination of antimicrobial activity and production of some metabolites by Pseudomonas aeruginosa B1 and B2 in sugar beet molasses. African J. Biotechnol. 7(24): 4614-4619.

2. Thu-Ha, T. T. (2007). Role of CLP massetolid A, in biological control of Phytophthora infestans and in colonization of Tomato plants by Pseudomonas fluorescens. $\mathrm{PhD}$ thesis. Wageningen University. The Netherland.

3. Souza, J.; Boer, M.; Waard, P.; Beek, T. and Raaijmakers, J. (2003). Biochemical, Genetic, and Zoosporicidal properties of CLP surfactants produced by Pseudomonas fluorescens. Appl. Environ. Microbiol. 69(12): 7161-7172.

4. Lee, J.; Moon, S.; and Hwang, B. (2003). Isolation and antifungal and antioomycete activities of aerugine produced by Pseudomonas fluorescens strain MM-B6. Appl. Environ. Microbiol. 69(4): 2023-2031.

5. Wilhelm, S.; Gdynia, A.; Tielen, P.; Rosenan, F. and Jaeger, K. (2007). The autotransporter Esterase Est A of Pseudomonas aeruginosa is required for rhamnolipid production, cell motility, and biofilm formation. J. of Bacteriol. 189(18): 6695-6703.

6. Maneerat, S. and Phetrong, K. (2007). Isolation of biosurfactant producing marine bacteria and characteristics of selected biosurfactant. J. Sci. Technol. 29(3): 781-791.

7. Thrane, C.; Olsson, T.; Nielsen, T. and Sqrensen, J. (1999). Vital fluorescent strains for detection of stress in Pythium ultimum and Rhizoctonia solani challenged with viscosinamide from Pseudomonas fluorescens DR54. Microbiol. Ecol. 30: 11-23.

8. Mozzola, M.; Zhao, X.; Cohen, M. and Raaijmakers, J. (2007). Cyclic lipopeptide surfactant production by Pseudomonas fluorescens SS101 is not required for suppression of complex Pythium Spp. populations. Phytopathology. 97(10): 13481355.

9. Moataza, M. S. (2006). Destruction of Rhizoctonia solani and Phytophthora capsici causing Tomato Root - rot by Pseudomonas fluorescens lytic enzymes. Res. J. Agricul. And Biolog. Sci. 2(6): 274-281.

10. Abouseoud, M.; Maachi, R.; Amrane, A.; Boudergua, S. and Nabi, A. (2008). Evaluation of different carbon and nitrogen sources in production of biosurfactant by Pseudomonas fluorescens. Desalination. 223: 143-151.

11. Guerra-Santos, L.; Kappel, O.; and Fiechter, A. (1984). Pseudomonas aeruginosa biosurfactant production in continuous culture with glucose as carbon source. Appl. Environ. Microbiol. 18(2): 301-305. 
12. Vioque, E. (1984). Spray reagent for thin-layer chromatography (TLC) and paper chromatography (PC). In: CRC Hand book of chromatography: Lipids. V2, pp. 309317. Zweig, G. and Shema, J. (eds). CRC. Press. Inc.

13. Al-Adhami, A.J. (2001). Use of polyphenol oxidase from wood-rooting fungi for actinocin production. Ph.D Thesis. Wroclaw University of Technology. Institute of Organic Chemistry. Poland.

14. Yalcin, E. and Ergene, A. (2009). Screening the antimicrobial activity of biosurfactant produced by microorganisms isolated from refinery wastewaters. J. Appl. Biolog. Sci. 3(2): 148-153.

15. Noudeh-Dehghan, G.; Moshafi, M.; Behravan, S. and Afzadi, M. (2009). Screening of three strains of Pseudomonas aeruginosa prediction of biosurfactant-producer strain. American J. Appl. Sci. 6(8): 1453-1457.

16. Cao, X.; Liao, Z.; Wang, C.; Yang, W. and Lu, M. (2009). Avaluation of lipopeptide biosurfactant from Bacillus natto TK-1 as a potential source of anti-adhesive, antimicrobial and antitumor activities. Brazilian. J. Microbiol. 40: 373-379.

17. Muthusamy, K.; Gopalakrishnan, S.; Ravi, T. and Sivachidambaram, P. (2008). Biosurfactant properties, commercial production and application. Current Sci. 94(25): 736-747.

18. Nielsen, T.; Sorensen, D.; Tobasen, C.; Anderson, J.; Christophersen, C.; Givkov, M. and Sorensen, J. (2002). Antibiotic and biosurfactant properties of cyclic lipopeptides produced by fluorescent Pseudomonas spp. from the sugar Beet rhizospher. Appl. Anviron. Microbiol. 68(7): 3416-3423.

19. Van-Dyke, M.; Couture, P.; Braner, M.; Lee, H. and Trevors, J. (1993). Pseudomonas aeruginosa UG3 rhamnolipid biosurfactants: Structural characterization and their use in removing hydrophobic compounds from soil. Can. J. Microbiol. 39: 1071-1077.

20. Javaheri, M.; Jennemam, G.; Mcinerney, M. and Kanapp, R. (1985). Anaerobic production of biosurfactant by Bacillus licheniformis JF- 2. Appl. Environ. Microbiol. 50: 698-700.

21. Singh, A.; Van Hamme, D. and Ward, O. (2006). Surfactants in microbiology and biotechnology: Part 2. Application aspects. Department of Biology. University of Waterloo, Ontario, Canada.

22. Okazaki, S.; Goto, M. and Furusaki, S. (2000). Surfactant - protease complex as a novel biocatalyst for peptide synthesis in hydrophilic organic solvents. Enzyme Microbiol. Technol. 26: 159-164.

23. Nielsen, T.; Sorensen, J.; Fels, J. and Pedersen, H. (1998). Secondary metabolite-and endochitinase dependent antagonism toward plant - pathogenic microfungi of Pseudomonas fluorescens isolates from sugar beet rhizospher. Appl. Environ. Microbiol. 64(10): 3563-3569 